\title{
Posttraumatic Bilateral Abducens Nerve Palsy: Mechanism of Injury and Prognosis
}

\author{
David J. Fam, Moogeh Baharnoori, Charles D. Kassardjian, Gustavo Saposnik
}

Keywords: Abducens Nerve, Bilateral, Head Injury, Ocular Motility, Trauma

doi:10.1017/cjn.2015.57

Can J Neurol Sci. 2015; 42: 344-346

Traumatic unilateral sixth nerve palsy is a relatively rare occurrence, with an estimated incidence between $1 \%$ and $2.7 \%$ of all head traumas. ${ }^{1}$ Bilateral sixth nerve palsies following trauma is even rarer and is often accompanied by additional neurological injury and fractures of the skull or cervical spine. ${ }^{1}$ Here, we describe an illustrative case of bilateral sixth nerve palsies following a motor vehicle accident and provide a review of the literature, differential diagnosis, the proposed mechanism of injury, and prognosis.

\section{CASE}

An 83-year-old female was the belted driver in a motor vehicle accident in which she drove off-road and collided with rocks. She was pulled from the car by bystanders before her car caught fire. Her Glasgow Coma Scale was reported as 15 when emergency services arrived, but she had amnesia for the events surrounding the accident. On arrival at the emergency department, she was stable with blood pressure $156 / 74$, heart rate 68 , respiratory rate 14 , and temperature $36.8^{\circ} \mathrm{C}$ with $97 \%$ oxygen saturation on room air. She had a large full-thickness laceration in the left supraorbital region that was sutured. A secondary survey did not reveal any additional signs of injury or burns. Chest and pelvis imaging did not reveal any fractures. After the patient was stabilized, her neurological examination revealed bilateral sixth nerve palsies. Duction testing revealed inability to abduct past the midline bilaterally compatible with -4 abduction deficits (supplemental video). She complained of binocular diplopia on both left and right horizontal gazes. The remainder of her neurological examination was normal. A head CT showed a fracture of the posterior wall of the left maxillary sinus and suspicion of a left temporal bone fracture (Figure 1A). There were multiple foci of hyperdensity in left frontal and right corona radiata compatible with hemorrhagic sheer injury (Figure 1B, C) and a left frontal convexity subdural hygroma. The cervical spine was cleared clinically and radiographically. A magnetic resonance imaging scan of the head showed no additional lesions to account for the sixth nerve palsies. There was no midline shift, herniation, mass effect, hydrocephalus, or involvement of the prepontine cistern. Magnetic resonance angiography was negative for dissection or aneurysm of the intracerebral circulation. At the time of discharge (12 days later), her deficits had not resolved and her double vision persisted at a 2-month follow-up appointment. After 1 year, the patient reported improved ability to abduct each eye but she complained of residual abduction palsies and diplopia and was scheduled for strabismus correction surgery in the upcoming month.

\section{DISCUSSION}

The abducens nerve (cranial nerve VI) is the longest cranial nerve, taking a tortuous course with several acute turns as it reaches the lateral rectus muscle. The nerve is susceptible to traumatic injury anywhere along this path, and localization requires familiarity with the details of its anatomy and the adjacent structures. The abducens nerve exits the brainstem at the pontomedullary junction close to the midline and travels anteriorly before turning vertically to ascend in the subarachnoid space over the clivus. It then dissects through the dura until it traverses over the ridge of the petrous bone and under the petroclinoidal (Gruber) ligament. This space is termed Dorello canal and is demarcated by Gruber ligament, the posterior clinoidal process, and the petrous bone. From here, the nerve passes through the cavernous sinus, then the superior orbital fissure to innervate the lateral rectus (Figure 2).

Lesions to the abducens nucleus itself will produce ipsilateral gaze palsy because of loss of interneurons travelling to the contralateral medical rectus in addition to the motor neurons directly innervating the lateral rectus. Alternatively, lesions of cranial nerve VI distal to the abducens nucleus result in deficient abduction of the ipsilateral eye. Fascicular lesions in the brainstem do not usually cause isolated sixth nerve palsies, and are often accompanied by injury to the seventh and eighth cranial nerves or pyramidal tract, termed the Millard-Gubler syndrome. A lesion in the cavernous sinus or superior orbital fissure may also produce deficits of third, fourth, and sixth cranial nerves. The presence of an ipsilateral Horner syndrome can distinguish between these latter two localizations because sympathetic fibers travel briefly with the abducens nerve in the cavernous sinus. A lesion to the lateral rectus muscle can occur with orbital fracture and muscle entrapment and will also present with ipsilateral loss of abduction. Additional localizing features of an orbital lesion include proptosis and optic nerve involvement.

In sixth nerve injury following head trauma without petrous bone fracture or additional neurological findings, the Dorello canal is considered the likeliest site for injury because the nerve

From the Division of Neurology, University of Toronto, Toronto, Ontario, Canada (DJF, MB, GS); Department of Neurology, Mayo Clinic, Rochester, Minnesota (CDK); Stroke Research Unit and Keenan Research Center, St. Michael`s Hospital, Toronto, Ontario, Canada (GS).

Received January 27, 2015. Final Revisions Submitted March 30, 2015 Correspondence to: Gustavo Saposnik, 55 Queen St E - Room 931, Toronto, ON, M5C 1R6 Canada. Email: saposnikg@smh.ca 

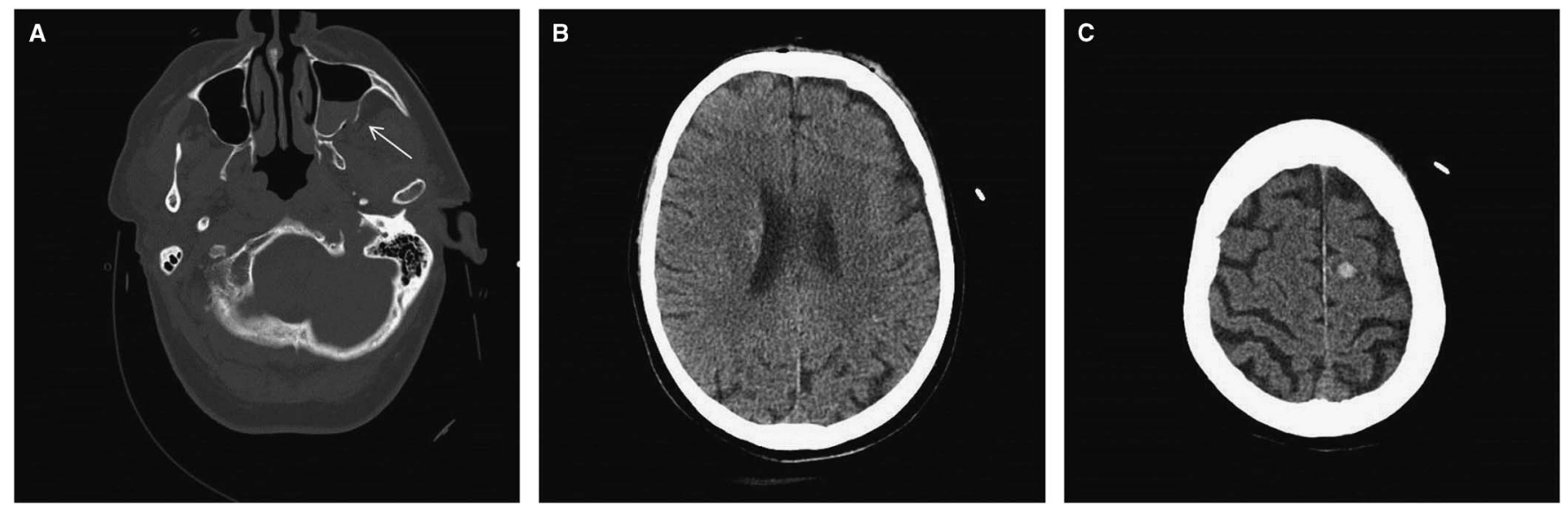

Figure 1: Nonenhanced brain CT at admission. (A) Bone view showing fracture of the posterior wall of the left maxillary sinus (white arrow), with associated high attenuation fluid in the sinus representing blood. $(B, C)$ Focal areas of hyperdense signals in the right corona radiata and high left frontal convexity, in keeping with hemorrhagic shear injuries.

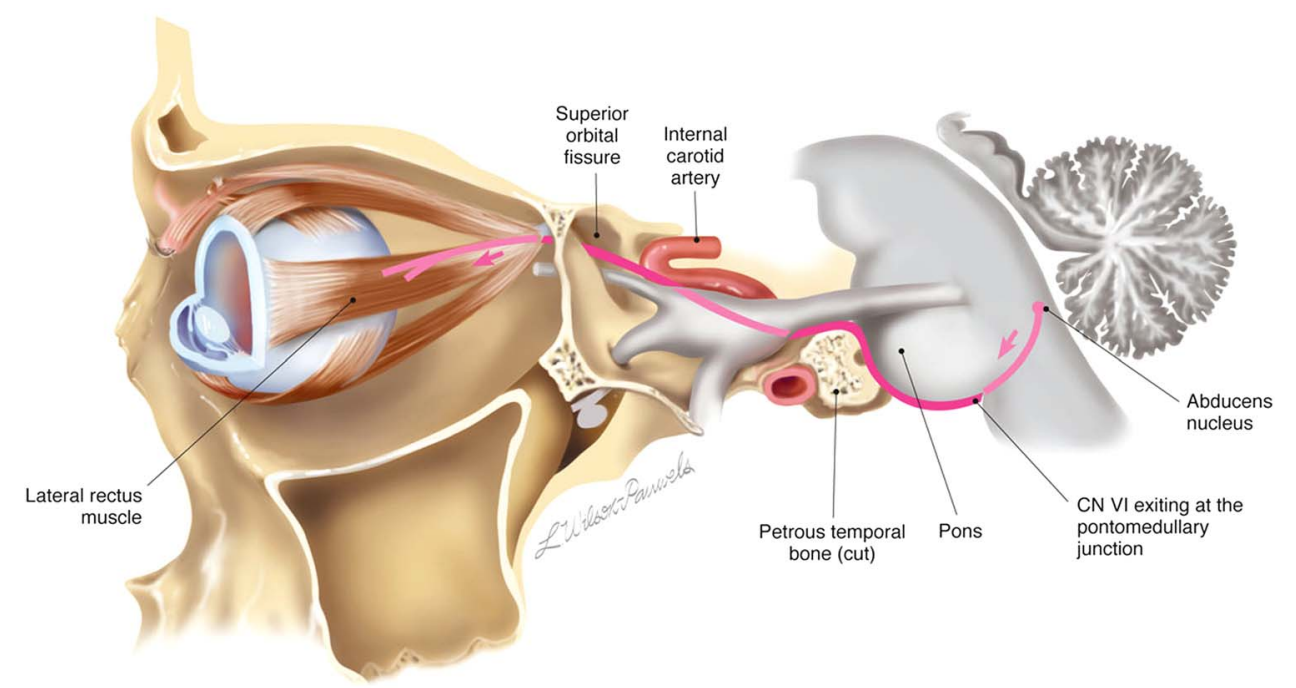

Figure 2: Overview of abducens nerve (VI) trajectory.

takes several sharp turns as it passes through the petroclinoidal region. However, imaging studies in these cases typically do not reveal a lesion there. ${ }^{1}$ The primary hypothesis for injury at this site is based on postmortem autopsy studies, and proposes that sufficient force generated during head injury causes downward displacement with shearing and contusion of the nerve against the petrous ridge in the tight space of the canal. In a few cases, delayed presentations of bilateral sixth nerve palsies have been observed and may be attributed to prolonged ischemia resulting from compromise to smaller vessels supplying the nerve. Finally, trauma can lead to intracranial or subarachnoid hemorrhage, retroclival hematoma, and hydrocephalus, which can raise intracranial pressure and cause acute or delayed bilateral sixth palsies. ${ }^{2}$ These findings are usually accompanied by other signs of increased intracranial pressure, including visual field deficit and papilledema. Our patient likely suffered from bilateral abducens contusions in Dorello canal given the absence of other brainstem signs or imaging findings, lack of intracranial hemorrhage, no evidence of petrous bone fracture, and no suggestion of bilateral lateral rectus trapping despite the left maxillary fracture.

Various studies have estimated the rate of spontaneous recovery from unilateral sixth nerve palsy anywhere from $12 \%$ to $73 \%$ by 6 months. ${ }^{1,3}$ In the case of bilateral palsies, this figure is substantially lower. In one study of eight patients, it was reported to be as low as $38 \% .^{3}$ The median time to recovery is approximately 90 days and 92 days in unilateral and bilateral cases, respectively. ${ }^{3}$ Table 1 contains a representative sample of selected cases of bilateral sixth nerve palsy along with outcome. In addition to bilateral involvement, severity of the abduction deficit is also independently associated with poorer outcome, with complete deficits having lower rates of spontaneous recovery. ${ }^{4}$ Most studies are limited by the small sample size; indeed, cases of bilateral sixth nerve palsy following trauma are probably rare because the force required is usually incompatible with life. For the same reason, traumatic bilateral sixth nerve palsies are frequently accompanied by life-threatening injuries such as cervical-spine and basilar skull fracture. $^{1}$ 
Table 1: Selected published articles on traumatic bilateral six nerve palsy describing the imaging findings, recovery rate, and time to recovery

\begin{tabular}{|c|c|c|c|c|c|c|}
\hline Author & No. of cases & $\begin{array}{l}\text { Average } \\
\text { age }\end{array}$ & $\begin{array}{l}\text { Spontaneous } \\
\text { recovery }\end{array}$ & $\begin{array}{l}\text { Time to } \\
\text { recovery }\end{array}$ & Intervention & Brain imaging \\
\hline Holmes et al (1998) & 8 & 22.5 & $38 \%$ & 92 days & No & NA \\
\hline Mutyala et al (1996) & 13 & NA & $12 \% *$ & NA & NA & NA \\
\hline Selcuk and Mut (2013) & 1 & 47 & Yes & 12 months & No & $\begin{array}{l}\text { MRI: contusion in parietal and occipital } \\
\text { lobes }\end{array}$ \\
\hline Pancko et al (2010) & 1 & 62 & Partial (2 months) & 2 months $\dagger$ & No & $\begin{array}{l}\text { CT: base of skull and sphenoid sinus } \\
\text { fracture }\end{array}$ \\
\hline Advani et al (2003) & 1 & 44 & Partial (6 months) & 6 months $\dagger$ & Surgery (11 months) & CT/MRI: normal \\
\hline Czyz et al (2011) & 1 & 48 & No & - & Surgery (10 months) & CT/MRI: normal \\
\hline Yanamadala et al (2012) & 1 & 41 & Yes & 6 months & No & CT: normal \\
\hline Katsuno et al (2007) & 1 & 29 & No & - & No & CT: skull base fracture \\
\hline Lopes et al (2011) & 1 & 45 & No & - & No & MRI: bilateral avulsion of six nerve \\
\hline Ruiz del Río et al (2006) & 1 & 72 & No & - & Botox (4 months) & $\begin{array}{l}\text { CT: intraventricular and subarachnoid } \\
\text { bleed, left orbit wall fracture }\end{array}$ \\
\hline Uchikado et al (1998) & 1 & 20 & Partial (12 months) & 12 months*, $\dagger$ & No & $\begin{array}{l}\text { CT: subarachnoid bleed, } \\
\text { pneumocephalus }\end{array}$ \\
\hline Kobayashi et al (1988) & 1 & 35 & Yes & 6 months & No & $\begin{array}{l}\text { CT: left temporal bone fracture, } \\
\text { pneumocephalus }\end{array}$ \\
\hline Salunke et al (2012) & 1 & 30 & No & - & No & CT: normal \\
\hline Chang et al (2009) & 1 & 35 & No & 6 months & Vascular embolization & $\begin{array}{l}\text { MRA: arteriovenous fistulae bilateral } \\
\text { inferior nasal conchae }\end{array}$ \\
\hline Ratilal et al (2006) & 1 & 26 & Yes & 1 month & No & CT: clival epidural hematoma \\
\hline Gaul et al (2002) & 1 & 42 & No & - & Botox & CT/MRI: normal \\
\hline Lee et al (2006) & 1 & 29 & Yes & 6 months & No & $\begin{array}{l}\text { CT: bilateral temporal bone (petrous } \\
\text { portion) fracture }\end{array}$ \\
\hline
\end{tabular}

*Kaplan-Meier survival curve was used to estimate 6-month recovery.

$\dagger$ Time to partial recovery

$\mathrm{MRA}=$ magnetic resonance angiography; $\mathrm{NA}=$ not available.

Treatment consists of patching one eye or the use of prisms. Long-term treatment can be achieved with botulinum toxin (BTX) injection or surgical intervention. Outcomes with BTX have shown mixed results. Although some studies suggest no benefit from BTX treatment, Hung et al showed improved recovery for patients with high-grade abduction deficits with BTX treatment versus conservative management suggesting a role for BTX in more severely affected patients who have a lower initial chance of spontaneous recovery (Table 1$).^{5}$

\section{CONCLUSIONS}

In summary, clinical presentation of bilateral cranial nerve VI nerve palsy is uncommon, usually following head trauma, and typically cooccurs with other injuries incompatible with life. As the longest intracranial nerve, the sixth nerve is vulnerable to injury anywhere along its path. In the absence of a petrous fracture or radiographically identifiable lesion, Dorello canal is the likeliest site for injury because of restricted space and close proximity of adjacent structures that can compress the nerve. Failure to abduct past the midline and bilateral presentation are independent risk factors for poor outcome with low rates of spontaneous recovery at 6 months. Persistent deficits can be treated through BTX or surgical intervention.

\section{Disclosures}

$\mathrm{DF}, \mathrm{GS}, \mathrm{MB}$, and CK have no conflicts of interest to declare.

\section{SUPPLEMENTARY MATERIAL}

To view supplementary material for this article, please visit http://dx.doi.org/10.1017/cjn.2015.57

\section{REFERENCES}

1. Advani RM, Baumann MR. Bilateral sixth nerve palsy after head trauma. Ann Emerg Med. 2003;41:27-31.

2. Yanamadala V, Walcott BP, Nahed BV, Coumans JC. Post-traumatic bilateral abducens nerve palsy with completed recovery. J Clin Neurosci. 2012;19:585-6.

3. Holmes JM, Droste PJ, Beck RW. The natural history of acute traumatic sixth nerve palsy or paresis. J AAPOS. 1998;2:265-8.

4. Holmes JM, Beck RW, Kip KE, Droste PJ, Leske DA. Predictors of nonrecovery in acute traumatic sixth nerve palsy and paresis. Ophthalmology. 2001;108:1457-60.

5. Hung HL, Kao LY, Sun MH. Botulinum toxin treatment for acute traumatic complete sixth nerve palsy. Eye (Lond). 2005;19:337-41. 